\title{
Sperm chromatin structure assay (SCSA): a tool in diagnosis and treatment of infertility
}

\author{
Mona Bungum, Leif Bungum and Aleksander Giwercman
}

Diagnosis of male infertility has mainly been based on the World Health Organization (WHO) manual-based semen parameter's concentration, motility and morphology. It has, however, become apparent that none of these parameters are reliable markers for evaluation of the fertility potential of a couple. A search for better markers has led to an increased focus on sperm chromatin integrity testing in fertility work-up and assisted reproductive techniques. During the last couple of decades, numerous sperm DNA integrity tests have been developed. These are claimed to be characterized by a lower intraindividual variation, less intralaboratory and interlaboratory variation and thus less subjective than the conventional sperm analysis. However, not all the sperm chromatin integrity tests have yet been shown to be of clinical value. So far, the test that has been found to have the most stable clinical threshold values in relation to fertility is the sperm chromatin structure assay (SCSA), a flow cytometric test that measures the susceptibility of sperm DNA to acid-induced DNA denaturation in situ. Sperm DNA fragmentation as measured by SCSA has shown to be an independent predictor of successful pregnancy in first pregnancy planners as well as in couples undergoing intrauterine insemination, and can be used as a tool in investigation, counseling and treatment of involuntary childlessness. More conflicting data exist regarding the role of sperm DNA fragmentation in relation to fertilization, pre-embryo development and pregnancy outcome in in vitro fertilization and intracytoplasmic sperm injection (ICSI).

Asian Journal of Andrology (2011) 13,69-75; doi:10.1038/aja.2010.73; published online 8 November 2010

Keywords: assisted reproductive techniques; infertility; sperm chromatin structure assay; sperm DNA

\section{INTRODUCTION}

In Western countries, up to one-fourth of couples in reproductive age are seeking medical help for involuntary childlessness. ${ }^{1}$

Diagnosis of male infertility has mainly been based on the traditional semen parameter's concentration, motility and morphology. It has, however, become apparent that none of these parameters recommended by the World Health Organization (WHO) ${ }^{2}$ are sufficient for the determination of male fertility capacity or for evaluation of the fertility potential of a couple.

The WHO parameters only address few aspects of sperm quality and function and this may explain why the discriminative power in relation to fertility is quite low. ${ }^{3,4}$

In parallel with the growing knowledge in the area of early reproductive function, the focus on the causes of infertility or subfertility in a couple has decreased. The work-up is often minimal and the fertility markers poor why many couples are diagnosed with so-called unexplained infertility. In fact, most men seeking medical help for involuntary childlessness never get an explanation for the causes lying behind their reduced semen quality.

On the other hand, the use of assisted reproductive techniques (ARTs) has increased substantially, in particular, intracytoplasmic sperm injection (ICSI). ${ }^{1,5}$ Although in the beginning of the era of ICSI the indication for treatment was severely reduced semen quality, even now couples with male partners, not having any apparent sperm defects, request for and are treated with ICSI. However, ART treatment is a symptomatic treatment, where only $25-30 \%$ of the treatments result in a child. ${ }^{6}$ One of the causes behind the limited success rate of ART can be the lack of markers to diagnose and find the underlying causes to male subfertility and also a lack of methods to identify the type of ART treatment giving the best chances of pregnancy in a given couple.

The search for more optimal predictors of fertility has resulted in a growing focus on the sperm DNA integrity. ${ }^{7,8}$ During the past decades, a variety of techniques to assess the sperm chromatin integrity have been developed. One of these methods is the sperm chromatin structure assay (SCSA), first described by Evenson et al. ${ }^{9}$ SCSA has shown to be an independent marker of fertility in vivo and may also have a potential to contribute to the more successful use of ART in the future. In this chapter, we will review how sperm DNA integrity as measured by SCSA can be used as a tool in diagnosis and treatment of involuntary childlessness.

\section{MALE INFERTILITY/SUBFERTILITY}

Etiology of male infertility/subfertility

Involuntary childlessness is a complex condition that can be a result of female or male as well as combined factors. In $20 \%$ of cases, the predominant cause is solely male-related and in another $30 \%$, anomalies in both partners contribute to the childlessness. ${ }^{2}$ Genital 
infections, endocrine disturbances and immunological factors have been regarded as the most common causes of male subfertility. However, to an increasing degree, genetic and other molecular causes have been identified as contributing explanatory factors, ${ }^{10}$ and among these are the occurrences of chromatin defects assessed as breaks in sperm nuclear DNA. ${ }^{7,11-14}$

In $60-75 \%$ of the male-caused cases, the etiology of reduced semen quality remains unexplained and is referred to as idiopathic infertility. $^{2}$

\section{Diagnosis of male infertility/subfertility}

Traditionally, the diagnosis of male infertility or subfertility is based on an analysis of sperm concentration, motility and morphology. ${ }^{2}$ However, as the analysis is mainly performed by light microscopy of 100-200 spermatozoa, the analysis is biased on a high level of subjectivity resulting in a higher grade of intralaboratory and interlaboratory variations, ${ }^{15,16}$ and therefore, a low predictive value of the WHO analysis is reported. The WHO parameters address only few aspects of sperm quality and function, and during the last decades, several other sperm function tests have been suggested and used, including vital staining, biochemical analysis of semen, hypo-osmotic swelling test, antisperm antibody test, sperm penetration assay, hemizona assay, reactive oxygen species (ROS) tests and computer-assisted sperm analysis. ${ }^{13}$ However, few of the tests are implemented in clinical routine. ${ }^{17}$

Partly owing to the low predictive value of the tests used in diagnosing male infertility or subfertility and partly owing to the growing availability and use of ART, the focus on the causes of infertility or subfertility has decreased. Such a switch in the routines for investigation of infertile couples implies that an increasing proportion of cases remain unexplained and the possibilities of developing a causal therapy become severely limited.

Although the origin and mechanisms responsible for sperm DNA damage are not yet fully understood, an increasing amount of data demonstrate an association between sperm DNA damage and fertility. ${ }^{7,11,12,14,18-21}$ As a consequence, it has been proposed that sperm DNA integrity could be a possible fertility predictor to be used as a supplement to the traditional sperm parameters. ${ }^{11,22,23}$

\section{Causes of sperm DNA damage}

Spermatogenesis is a complex process of male germ cell proliferation and maturation from immature diploid to mature haploid spermatozoa, ${ }^{24}$ where damage of sperm DNA or its chromatin structure can occur at any step (reviewed in Ref. 7). It has been proposed that DNA damage in sperm can be because of unrepaired DNA breaks during the spermatogenetic chromatin remodeling and packaging or abortive apoptosis during spermatogenesis. Other possible causes are the effect of endogenous endonucleases and caspases, exposure to a variety of genotoxic agents because of therapeutic reasons or because of occupational or environmental exposures, and finally, the action of oxidative damage. ${ }^{14}$ Most likely, these factors are interrelating. A defective checkpoint at the crossing-over process during spermatogenesis or deficiencies in the protamination process will likely make the sperm more vulnerable to oxidative stress (OS) at a later moment. The mechanism that probably, for which most evidence exists, is the OS caused by an imbalance between the antioxidant ability in seminal plasma and the production of ROS, leading to the formation of oxidative products such as $8 \mathrm{OHdG}$. The sperm cell membrane, being rich in unsaturated fatty acids, is easily attacked by ROS with further detrimental effects on nuclear membranes as well as on sperm DNA. ${ }^{25}$ Furthermore, sperms lack antioxidants and DNA repair systems, ${ }^{26}$ and protection of the offspring from the negative effects of DNA strand breaks originating from the spermatozoa is completely dependent on the repair capacity of the oocyte and the early embryo. Leukocytes and abnormal spermatozoa in the semen are the main sources of ROS in semen; $;^{14,27,28}$ however, increased scrotal temperature due to illness such as fever ${ }^{29-31}$ or varicocele ${ }^{32}$ are other reported sources. Also, older men are reported to have sperm with more DNA fragmentation than younger men, which is likely because of OS. ${ }^{33-37}$ Moreover, smokers have an increased level of oxidative damage in their sperm DNA compared with non-smokers. ${ }^{38-44}$

\section{Analysis of sperm DNA fragmentation}

Currently, three major tests of sperm DNA fragmentation are most frequently used, including the Comet assay (single-cell gel electrophoresis), ${ }^{45-47}$ the terminal deoxynucleotidyl transferase-mediated dUDP nick end-labeling (TUNEL) assay $^{48}$ and the SCSA., ${ }^{91}$ Comet, TUNEL and SCSA all label single- or double-stranded DNA breaks; however, unfortunately, most of the available techniques for detection of sperm DNA damage provide limited information on the nature of the DNA lesions detected and none of them enable us to depict the exact etiology and pathogenesis of impairment of sperm DNA.

Whereas Comet assay is a fluorescence microscopic test, TUNEL assay can be applied both in bright field/fluorescence microscopy and by flow cytometry. In Comet, sperm cells are mixed with melted agarose and then placed on a glass slide. The cells are lysed and then subjected to horizontal electrophoresis. DNA is visualized with the help of a DNA-specific fluorescent dye and DNA damage is quantified by measuring the displacement between the genetic material of the nucleus comet head and the resulting tail. In the TUNEL assay, terminal deoxynucleotidyl transferase incorporates labeled (by and large, fluorescent) nucleotides to 3 '-OH at single- and double-strand DNA breaks to create a signal, which increases with the number of DNA breaks. The fluorescence intensity of each scored sperm is determined as 'positive' or 'negative' for sperm on a microscope slide. In a flow cytometer, the fraction of positive sperm is represented by the cells above a threshold channel value on a relative fluorescence intensity scale.

SCSA is a flow cytometric test where sperm DNA breaks can be evaluated indirectly through the DNA denaturability. The assay measures the susceptibility of sperm DNA to acid-induced DNA denaturation in situ, followed by staining with the fluorescent dye acridine orange. ${ }^{9,11,49}$ By using a flow cytometer, 5000-10 000 sperms can be analyzed within few seconds and thus provides a less subjective result compared with the WHO analysis where only 1-300 cells are analyzed. Through a specific SCSA software (SCSA-Soft; SCSA Diagnostics, Inc., Brookings, SD, USA), a scatter plot is created, showing the ratio of green and red sperm. The percentage of red sperm is called DNA fragmentation index (DFI), ${ }^{11}$ visualized by a histogram (Figure 1). These are the sperms with denaturated DNA.

The sperm with the most intensive green color is called high DNA stainable (HDS) sperm. It is still unclear about the precise mechanisms and types of DNA damage that are lying behind DFI and HDS; however, it is believed that DFI is related to the percentage of sperm with DNA breaks or protamine defects. HDS is thought to represent immature spermatozoa. ${ }^{11}$

SCSA is only one of the several methods evaluating sperm DNA integrity. However, so far, it is the only method, which has demonstrated clear and clinically useful cutoff levels for inferring male fertility potential. ${ }^{9,22,23,49}$ SCSA is a standardized test. ${ }^{11}$ It is performed 


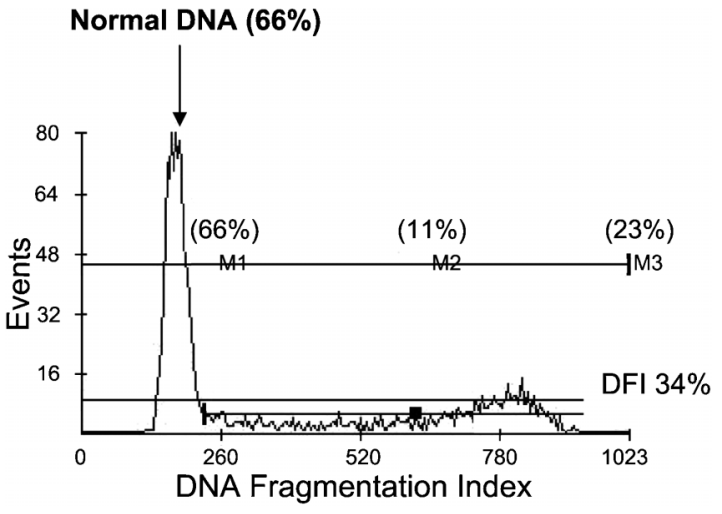

Figure 1 Histogram of an SCSA analysis of a sperm sample with a high DFI. The normal population of sperm ( $66 \%$ of all spermatozoa) is indicated by the arrow. Thirty-four percent of the sperm have abnormal packaged DNA why DFI is $34 \%$. DFI, DNA fragmentation index; SCSA, sperm chromatin structure assay.

according to a strict protocol, ${ }^{11}$ and a specific dedicated software (SCSA-Soft) is used to analyze the flow cytometric data. Apart from being subjected to a very limited intralaboratory variation, ${ }^{50}$ however, the SCSA analysis has shown to be very robust to variation between laboratories. In an external quality control based on $>180$ samples, a high $(r=0.8)$ correlation was found between the values obtained by our laboratory and those from a control laboratory. Furthermore, not only was there a high level of correlation between the results reported by two independent laboratories that strictly followed the SCSA protocol, but the absolute DFI values obtained at two different places, using different equipments, did not, on average, differ by $>1 \%{ }^{51}$

Studies have demonstrated that these three sperm DNA integrity tests, SCSA, TUNEL and Comet assays, generally correlate moderately with each other (a coefficient of correlation between 0.4 and 0.7 ), which indicates that the tests likely are expressing different aspects of sperm DNA damage.

\section{SCSA and the chance of spontaneous pregnancy}

Two population-based studies, a US study including 165 couples $^{9}$ and a Danish study including 215 couples, ${ }^{49}$ have demonstrated that DFI as measured with SCSA is an excellent predictor of subfecundity in the normal population. The results of these two studies were in well accordance with each other and also independent of other standard sperm parameters. In the interval of DFI 0-20\%, the chance of spontaneous pregnancy was constant. When DFI was $>20 \%$, the chance of obtaining a spontaneous pregnancy was decreased and close to zero, when the DFI level passed 30-40\%. Even though DFI was $<20 \%$, only $13 \%$ of all cycles resulted in a pregnancy. Therefore, in a normal population, not selected because of infertility problems, SCSA is a valuable tool to identify men who are at risk of not giving rise to a pregnancy. It is not possible to get the same information from the traditional WHO sperm parameters. Even among men with low sperm concentration, poor motility or morphology, there will be men with a certain potential of fertility. ${ }^{3}$

Almost similar results were obtained in a recent Swedish case-control study of 137 infertile and 127 fertile men. ${ }^{23}$ The risk of being infertile was found to be increased when DFI, as measured by SCSA, was $>20 \%$ in men with normal standard semen parameters, an odds ratio (OR) of 5.1 (confidence interval (95\% CI): 1.2-23), compared with fertile controls. If one of the WHO parameters were abnormal, the OR for infertility would already increase at a DFI $>10 \%$ (OR: 16; CI: $4.2-60$ ). A DFI $>20 \%$ was found in $40 \%$ of the men with otherwise

\section{DNA fragmentation index (DFI)}

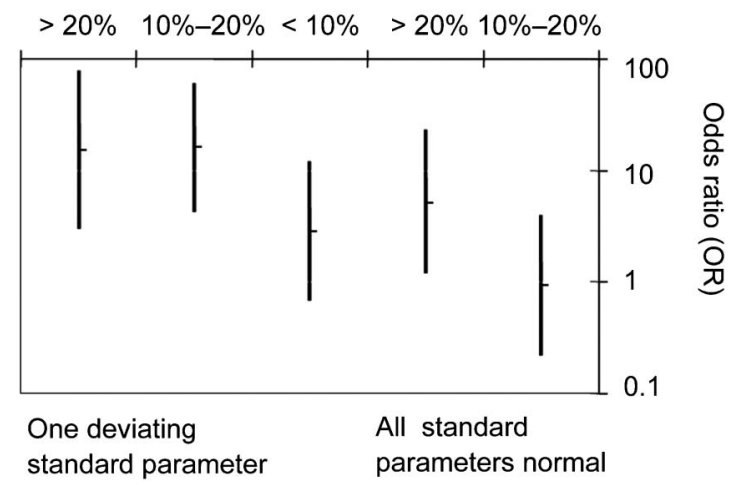

Figure 2 OR for infertility in vivo in relation to standard sperm parameters and different DFI levels: $<10 \%, 10-20 \%$ and $>20 \%$. Data are OR $(95 \% \mathrm{Cl})$. Cl, confidence interval; DFI, DNA fragmentation index; OR, odds ratio.

normal standard parameters. DFI was also shown to be an independent predictor of spontaneous pregnancy (Figure 2). In another study of 350 Swedish men from infertile couples, Erenpreiss et al. ${ }^{52}$ found that $20 \%$ of the men with otherwise normal WHO sperm parameters had a SCSA-DFI $>20 \%$.

The association between sperm DNA damage and the traditional semen parameters is shown to be only weak-to-moderate. ${ }^{51,53}$ It is also shown that $25-40 \%$ of infertile men may have normal standard sperm characteristics according to WHO criteria, but a DFI $>20-30 \%$. $^{2,23,52}$

\section{SCSA and the chance of pregnancy in ART}

ART includes all technologies that involve the handling of sperm outside the body, as in intrauterine insemination (IUI), or handling of oocytes, sperm and embryos as in in vitro fertilization (IVF) and ICSI. ${ }^{54}$ In IVF, the spermatozoa's ability to penetrate the zona pellucida of the oocyte is utilized. In ICSI, however, one single spermatozoon is selected and injected directly into the cytoplasm of the oocyte. Owing to these differences, it may not be correct to report results from the three types of treatments together, as has been the case in most of the published SCSA studies. In those studies reporting the three treatment types separately, the number of patients is included and thus the statistical power has generally been relatively low. The first SCSA study to indicate an association between sperm DNA damage and reduced pregnancy chances was published by Saleh et al., ${ }^{55}$ who performed a small study where 12 of 19 couples had a DFI value as measured by SCSA $>28 \%$ and no pregnancy was obtained. Boe-Hansen et al. ${ }^{56}$ in a study on 48 IUI couples found only two couples with a DFI value $>30 \%$, and even here pregnancy was obtained. Recently, in a study of 387 IUI cycles, we have shown that even in IUI, SCSA-DFI can be used as an independent predictor of fertility. ${ }^{22}$ Although the proportion of children born per cycle was $19 \%$ when the DFI value was $<30 \%$, those with a DFI value $>30 \%$ only had a take-home-baby rate of $1.5 \%$. In this group, the OR for delivery in relation to a DFI $<30 \%$ was 0.07 (95\% CI: 0.01-0.48; Figure 3).

In the same study, 388 IVF and 223 ICSI cycles were included. For these couples, it was not possible to find any threshold value for DFI that could predict the result of the treatments. However, when DFI was $>30 \%$, the result of ICSI was significantly better than that of IVF (OR for delivery was 2.17; CI: 1.04-4.51). These data are in agreement with other previous smaller reports using TUNEL or Comet assays, showing that sperm DNA damage is more predictive in IVF and much less so in ICSI. ${ }^{57}$ Also, a very recent study, ${ }^{58}$ using Comet, has shown that 




Figure 3 OR for outcome of IUI treatment in relation to threshold level for the DFI. Data are OR $(95 \% \mathrm{Cl})$. Cl, confidence interval; DFI, DNA fragmentation index; IUI, intrauterine insemination; $\mathrm{OR}$, odds ratio.

the difference in percentage of sperms with impairment of DNA integrity, when comparing successful and unsuccessful treatment, is much more clear for IVF than for ICSI. In contrast, one single study, not discriminating the 100 IVF or ICSI treatments included, reported that DFI threshold values were not valid. ${ }^{59}$ Although available data indicate that ICSI may be the most effective ART treatment in couples where DFI is $>30 \%$, new prospective, randomized controlled studies testing whether there is a difference between IVF and ICSI with regard to pregnancy outcome should be performed. With regard to this issue, the power of the available studies is not strong enough.

In our study, no associations between fertilization rates and levels of sperm DNA damage were seen. This is in line with findings from most other recent studies using SCSA ${ }^{22,60-64}$ or other sperm DNA integrity assays. ${ }^{45,65-71}$ On the other hand, the presence of damaged sperm DNA was shown to have a significant inverse relationship with fertilization in other studies. ${ }^{40,57}$ Although some authors have reported similar cleavage stage embryo developmental rates between high and low DFI groups as measured by SCSA, ${ }^{56,59-61}$ others have shown that sperm DNA damage is negatively correlated with embryo quality after IVF and ICSI. ${ }^{32,40,45}$ Two studies have also reported that men with high levels of DNA fragmentation are at increased risk of low blastocyst formation compared with men with a low DFI. ${ }^{62,72}$

Although fertilization and embryo development may be independent of sperm DNA integrity, it has been suggested that the post-fertilization development of the pre-embryo can be impaired by such incomplete or aberrant sperm DNA repair by the oocyte leading to early miscarriages ${ }^{57}$ or in the worst cases, diseases in the offspring. $8,73,74$ In our study of about 1000 couples, no relationship was seen between sperm DNA fragmentation and unexplained pregnancy loss. ${ }^{22}$

The other SCSA parameter, HDS, was neither in our study nor in other studies found to be of predictive value of pregnancy.

\section{SCSA - intraindividual variation}

One of the main problems with using sperm quality as a diagnostic tool is the huge intraindividual variation reported for sperm concentration, motility and morphology.

In contrast, the first SCSA reports found a low intraindividual variation for DFI. ${ }^{9}$ In our hands, however, a significant day-to-day variation in infertile men with a coefficient of variation of about $30 \%$ is seen. ${ }^{75,76}$ This is in line with the intraindividual variation reported for the other standard sperm parameters. ${ }^{15,16}$ In all, $37 \%$ of patients having a DFI $>30 \%$ in the first test had a DFI $<30 \%$ in the second test. ${ }^{75} \mathrm{~A}$ total of $27 \%$ of those with DFI values in the range of $20-30 \%$ in the first test had a DFI $>30 \%$ in the second test. However, our recent data have demonstrated that, despite this apparent intraindividual variation, a single SCSA analysis performed on a random day in relation to the infertility work-up or to the conception is a strong predictor of infertility. ${ }^{23}$ In other words, the relatively high intraindividual variation for DFI does not invalidate the SCSA as a clinically useful marker of subfertility. Moreover, data from a so far unpublished study support this statement. Among 616 men who had their semen analyzed by SCSA both in infertility work-up and in the actual ART cycle, $85 \%$ of the men remained in the same category of DFI; $\leqslant 30 \%$ or $>30 \%$ from the first to second measurement. This implies that only in $15 \%$ of men a repeated analysis implied a reclassification of the SCSA-based prediction of fertility potential of the patient. $^{76}$

\section{DIVERGING POINTS OF VIEW REGARDING THE CLINICAL USEFULNESS OF THE SCSA TEST}

Although data, convincing with regard to clinical usefulness, are available, sperm DNA integrity testing in the daily clinical practice is still widely debated. During the last couple of years, some authors have challenged the clinical value of the SCSA test. ${ }^{77}$

One such example is a recent publication from the Practice Committee of the American Society for Reproductive Medicine (ASRM) ${ }^{78}$ Although ASRM, after a meta-analysis on 14 published studies, based on SCSA, TUNEL and Comet assays, stated that fragmented sperm DNA is more frequent in infertile than in fertile and may contribute to poor reproductive performance, they concluded that, so far, there is no proven role for routine DNA integrity testing in the evaluation of infertility. Other examples contributing to the debate are two other meta-analyses including both TUNEL and SCSA studies. Both Collins and co-workers, ${ }^{79}$ who considered 13 IVF/ICSI studies (nine carried out by SCSA and four by the TUNEL assay), and Zini and co-workers, ${ }^{80}$ who considered nine IVF (six carried out by TUNEL assay and three by SCSA) and 11 ICSI studies (six carried out by SCSA and five by the TUNEL assay) found only small associations between DFI and pregnancy outcome in IVF and ICSI. On the other hand, Barratt in an Editorial in Molecular Human Reproduction $(2010)^{81}$ claims that '.. there is an urgent need to develop new assessments of male reproductive potential and testing of DNA and its packaging in the human spermatozoa is likely to be a very important tool in the armamentarium'. Importantly, there are already considerable data to support the clinical use of DNA damage assays and in particular the SCSA.

In our opinion, there are several reasons for the confusion regarding the clinical usefulness of sperm DNA integrity testing. First of all, the vast majority of studies are based on small patient cohorts and are, therefore, underpowered. Second, most available reports focus on difference between fertile and infertile subjects in percentage of sperms with DNA damage rather than on predictive value of these tests in a clinical set-up; third, in the previously mentioned ASRM reports and meta-analysis, no discrimination is made between the results obtained by different methods for sperm DNA testing, SCSA, Comet and TUNEL. Last, uniform criteria for selection of patients for these studies are lacking. For instance, in many studies, no consideration is taken to the possible contribution of the female partner. Furthermore, to reach higher number of patients, couples receiving different types of ART are 
pooled together. As indicated above, sperm DNA testing seems to be the most powerful predictor for in vivo fertility and among the two in vitro methods, more related to the outcome of IVF than that of ICSI.

So far, clinical threshold values have only been established for the SCSA. Two meta-analyses including only SCSA studies have been performed. Although Evenson and Wixon based on 14 papers ${ }^{18}$ reported that in IVF and ICSI, clinical pregnancy was closely related to DFI as measured by SCSA. Li et al. ${ }^{63}$ based on three papers found that DFI did not influence the chance of clinical pregnancy after IVF or ICSI treatment. In general, the interpretation of meta-analysis should be made carefully, as they are vulnerable to biases and confounding factors inherent in the original data. A particular problem with the latter study is the low number of patients included in the analysis.

\section{SCSA-CLINICAL RECOMMENDATIONS}

SCSA represents a valuable tool in diagnosis and treatment of infertility. The usefulness of the method is, however, first of all relating to in vivo fertility and, in particular, in couples diagnosed with the so-called unexplained infertility. In $20 \%$ of couples where the man has otherwise normal semen parameters and they fulfil the criteria for IUI, the DFI is $>30 \%$. In these couples, the chance of pregnancy is close to zero $^{22}$ and therefore, they should be referred directly to IVF/ICSI. By such a strategy change, one-fifth of all couples who normally are referred to IUI can avoid the physical and psychological burden that an unsuccessful ART treatment represents.

Up to $40 \%$ of all unexplained infertility cases can be related to a high DFI. In a couple where DFI is between $20 \%$ and $30 \%$, time to pregnancy will be longer than in those with a lower DFI level-information that can be utilized in counseling the couple. Combining SCSA analysis with assessment of traditional sperm parameters, gives a higher precision in the prediction of fertility. If one of the traditional sperm parameters is abnormal, fertility is reduced already at a DFI $>10 \%$.

In couple where DFI is $>30 \%$, IVF or ICSI should be chosen as the first choice treatment. See flow chart for the recommended use of SCSA in diagnosis and treatment of infertility (Figure 4).

However, as very few clinics have implemented sperm chromatin integrity testing, many couples are not aware of their actual sperm DNA defects and thus the choice of treatment is often inadequate. One reason for the relatively low implementation rate of SCSA is the necessity of a flow cytometer to perform the analysis. Very few laboratories have access to such equipment. On the other hand, sperm samples can be stored at $-80^{\circ} \mathrm{C}$ and shipped to a centralized SCSA laboratory.

Because of the relatively high intraindividual variation shown in the largest studies, one should recommend repeated SCSA testing in only

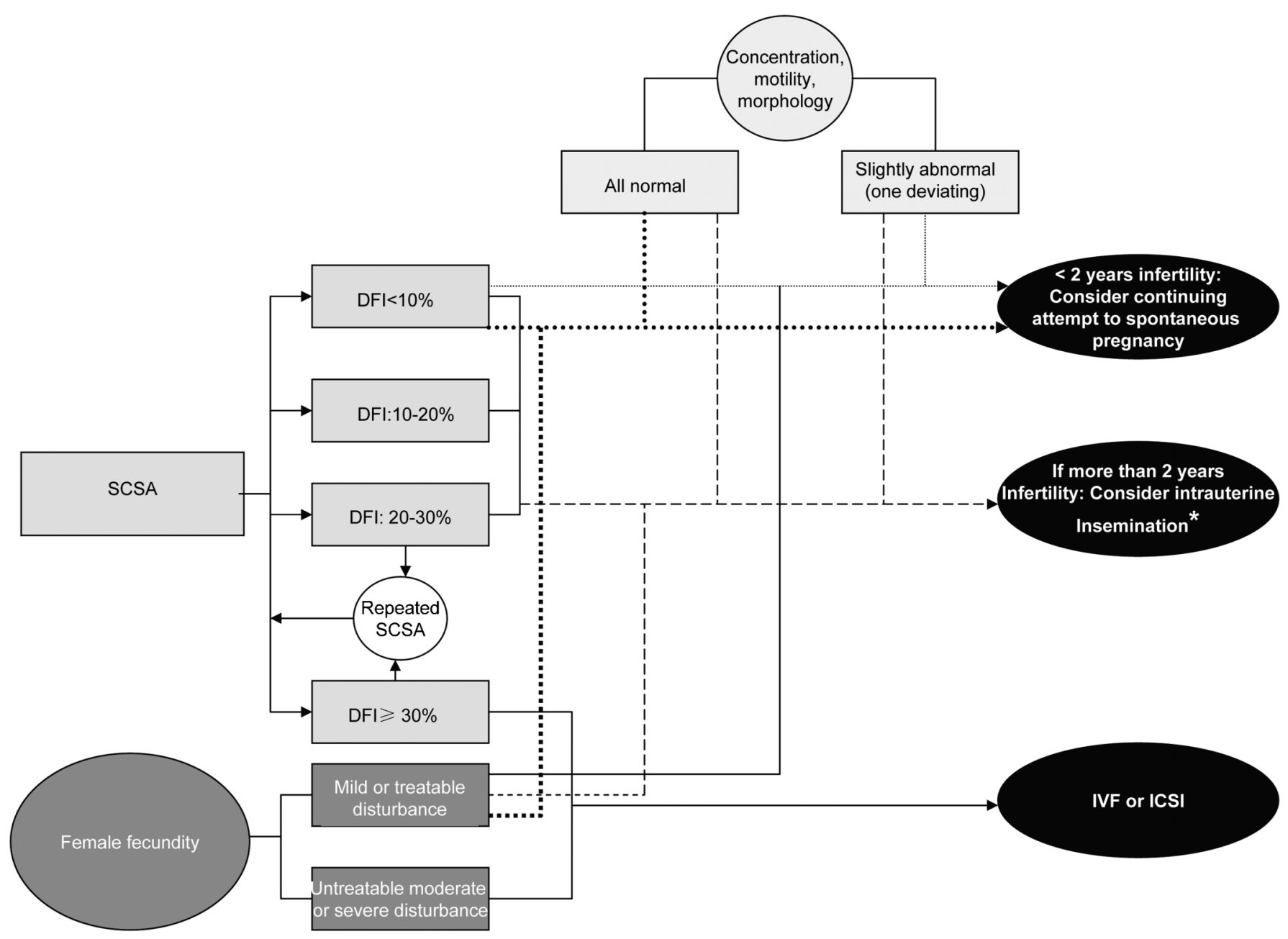

Figure 4 Flow chart for a possible use of SCSA in diagnosis and treatment of infertility. SCSA, sperm chromatin structure assay. *if DFI $\leqslant 25 \%$, DFI, DNA fragmentation index. 
those men who were not ICSI candidates, and having a DFI $>20 \%$ as in this subgroup, a switch of DFI to a higher level may have implications for the selection of the ART treatment (Figure 4).

A significant amount of disturbances in sperm DNA integrity is thought to be a result of OS caused by free oxidative radicals in semen. Some reports where men with a high DFI have been treated with antioxidant therapy have been published; however, the study populations have been small and data conflicting. ${ }^{35,82-87}$ Moreover, the underlying causes to the high sperm DNA damage in the study populations were not known. Despite this, it should not be neglected that SCSA in the future may have the potential to not only predict the chance of fertility in vivo or in vitro, but also to give indications for a causal treatment of disturbances of male fertility.

Development of newly improved tests depicting the cause of sperm DNA damage is the next step in extended use of sperm DNA integrity testing as a tool in diagnosis and treatment of involuntary childlessness.

\section{COMPETING FINANCIAL INTERESTS}

The authors declare no competing financial interests.

1 Dunson DB, Baird DD, Colombo B. Increased infertility with age in men and women. Obstet Gynecol 2004; 103: 51-6.

2 WHO. WHO Laboratory Manual for the Examination and Processing of Human Semen. Cambridge: WHO Press; 2010.

3 Guzick DS, Overstreet JW, Factor-Litvak P, Brazil CK, Nakajima ST et al. Sperm morphology, motility, and concentration in fertile and infertile men. N Engl J Med 2001; 345: 1388-93.

4 Bonde JP, Ernst E, Jensen TK, Hjollund NH, Kolstad $\mathrm{H}$ et al. Relation between semen quality and fertility: a population-based study of 430 first-pregnancy planners. Lancet 1998; 352: 1172-7.

5 Andersen AN, Goossens V, Ferraretti AP, Bhattacharya S, Felberbaum R et al. Assisted reproductive technology in Europe, 2004: results generated from European registers by ESHRE. Hum Reprod 2008; 23: 756-71.

6 Andersen AN, Gianaroli L, Felberbaum R, de Mouzon J, Nygren KG. Assisted reproductive technology in Europe, 2001. Results generated from European registers by ESHRE. Hum Reprod 2005; 20: 1158-76.

7 Erenpreiss J, Spano M, Erenpreisa J, Bungum M, Giwercman A. Sperm chromatin structure and male fertility: biological and clinical aspects. Asian J Androl 2006; 8: 11-29.

8 Agarwal A, Said TM. Role of sperm chromatin abnormalities and DNA damage in male infertility. Hum Reprod Update 2003; 9: 331-45.

9 Evenson DP, Darzynkiewicz Z, Melamed MR. Relation of mammalian sperm chromatin heterogeneity to fertility. Science 1980; 210: 1131-3.

10 Ferlin A, Raicu F, Gatta V, Zuccarello D, Palka G et al. Male infertility: role of genetic background. Reprod Biomed Online 2007; 14: 734-45.

11 Evenson DP, Larson KL, Jost LK. Sperm chromatin structure assay: its clinical use for detecting sperm DNA fragmentation in male infertility and comparisons with other techniques. J Androl 2002; 23: 25-43.

12 Spano M, Seli E, Bizzaro D, Manicardi GC, Sakkas D et al. The significance of sperm nuclear DNA strand breaks on reproductive outcome. Curr Opin Obstet Gynecol 2005; 17: 255-60.

13 Aitken RJ, de Iuliis GN, McLachlan RI. Biological and clinical significance of DNA damage in the male germ line. Int J Androl 2009; 32: 46-56.

14 Sakkas D, Alvarez JG. Sperm DNA fragmentation: mechanisms of origin, impact on reproductive outcome, and analysis. Fertil Steril 2010; 93: 1027-36.

15 Cooper TG, Neuwinger J, Bahrs S, Nieschlag E. Internal quality control of semen analysis. Fertil Steril 1992; 58: 172-8.

16 Neuwinger J, Behre HM, Nieschlag E. External quality control in the andrology laboratory: an experimental multicenter trial. Fertil Steril 1990; 54: 308-14.

17 Muller $\mathrm{CH}$. Rationale, interpretation, validation, and uses of sperm function tests. $J$ Androl 2000; 21: 10-30.

18 Evenson D, Wixon R. Meta-analysis of sperm DNA fragmentation using the sperm chromatin structure assay. Reprod Biomed Online 2006; 12: 466-72.

19 Tarozzi N, Bizzaro D, Flamigni C, Borini A. Clinical relevance of sperm DNA damage in assisted reproduction. Reprod Biomed Online 2007; 14: 746-57.

20 Zini A, Libman J. Sperm DNA damage: importance in the era of assisted reproduction. Curr Opin Urol 2006; 16: 428-34.

21 Zini A, Sigman M. Are tests of sperm DNA damage clinically useful? Pros and cons. $J$ Androl 2009; 30: 219-29.

22 Bungum M, Humaidan P, Axmon A, Spano M, Bungum L et al. Sperm DNA integrity assessment in prediction of assisted reproduction technology outcome. Hum Reprod 2007; 22: 174-9.
23 Giwercman A, Lindstedt L, Larsson M, Bungum M, Spano M et al. Sperm chromatin structure assay as an independent predictor of fertility in vivo: a case-control study. Int J Androl 2010 33: e221-7

24 de Kretser DM, Loveland KL, Meinhardt A, Simorangkir D, Wreford $\mathrm{N}$ et al. Spermatogenesis. Hum Reprod 1998; 13: 1-8.

25 Aitken RJ, Krausz C. Oxidative stress, DNA damage and the $Y$ chromosome. Reproduction 2001; 122: 497-506.

26 Aitken RJ, Baker MA, Sawyer D. Oxidative stress in the male germ line and its role in the aetiology of male infertility and genetic disease. Reprod Biomed Online 2003; 7: 65-70.

27 Aitken RJ, Buckingham D, West K, Wu FC, Zikopoulos K et al. Differential contribution of leucocytes and spermatozoa to the generation of reactive oxygen species in the ejaculates of oligozoospermic patients and fertile donors. J Reprod Fertil 1992; 94: 451-62.

28 Saleh RA, Agarwal A, Kandirali E, Sharma RK, Thomas AJ et al. Leukocytospermia is associated with increased reactive oxygen species production by human spermatozoa. Fertil Steril 2002; 78: 1215-24.

29 Evenson D, Jost L. Sperm chromatin structure assay is useful for fertility assessment. Methods Cell Sci 2000; 22: 169-89.

30 Evenson DP, Jost LK, Baer RK, Turner TW, Schrader SM. Individuality of DNA denaturation patterns in human sperm as measured by the sperm chromatin structure assay. Reprod Toxicol 1991; 5: 115-25.

31 Sergerie M, Mieusset R, Croute F, Daudin M, Bujan L. High risk of temporary alteration of semen parameters after recent acute febrile illness. Fertil Steril 2007; 88: 970.e1-7.

32 Saleh RA, Agarwal A, Sharma RK, Said TM, Sikka SC et al. Evaluation of nuclear DNA damage in spermatozoa from infertile men with varicocele. Fertil Steril 2003; 80: 1431-6.

33 Plastira K, Angelopoulou R, Mantas D, Msaouel P, Lyrakou S etal. The effects of age on the incidence of aneuploidy rates in spermatozoa of oligoasthenozoospermic patients and its relationship with ICSI outcome. Int J Androl 2007; 30: 65-72.

34 Moskovtsev SI, Willis J, Mullen JB. Age-related decline in sperm deoxyribonucleic acid integrity in patients evaluated for male infertility. Fertil Steril 2006; 85: 496-9.

35 Silver EW, Eskenazi B, Evenson DP, Block G, Young S et al. Effect of antioxidant intake on sperm chromatin stability in healthy nonsmoking men. J Androl 2005; 26: 550-6.

36 Spano M, Kolstad AH, Larsen SB, Cordelli E, Leter G et al. The applicability of the flow cytometric sperm chromatin structure assay in epidemiological studies. Asclepios. Hum Reprod 1998; 13: 2495-505.

37 Singh NP, Muller $\mathrm{CH}$, Berger RE. Effects of age on DNA double-strand breaks and apoptosis in human sperm. Fertil Steril 2003; 80: 1420-30.

38 Fraga CG, Motchnik PA, Wyrobek AJ, Rempel DM, Ames BN et al. Smoking and low antioxidant levels increase oxidative damage to sperm DNA. Mutat Res 1996; 351: 199-203.

39 Potts RJ, Newbury CJ, Smith G, Notarianni LJ, Jefferies TM. Sperm chromatin damage associated with male smoking. Mutat Res 1999; 423: 103-11.

40 Sun JG, Jurisicova A, Casper RF. Detection of deoxyribonucleic acid fragmentation in human sperm: correlation with fertilization in vitro. Biol Reprod 1997; 56: 602-7.

41 Saleh RA, Agarwal A, Nelson DR, Nada AE, El-Tonsy MH et al. Increased sperm nuclear DNA damage in normozoospermic infertile men: a prospective study. Fertil Steril 2002; 78: 313-8.

42 Sepaniak S, Forges T, Gerard H, Foliguet B, Bene MC et al. The influence of cigarette smoking on human sperm quality and DNA fragmentation. Toxicology 2006; 223 : 54-60.

43 Robbins WA, Vine MF, Truong KY, Everson RB. Use of fluorescence in situ hybridization (FISH) to assess effects of smoking, caffeine, and alcohol on aneuploidy load in sperm of healthy men. Environ Mol Mutagen 1997; 30: 175-83.

44 Rubes J, Lowe X, Moore D, Perreault S, Slott V et al. Smoking cigarettes is associated with increased sperm disomy in teenage men. Fertil Steril 1998; 70: 715-23.

45 Morris ID, Ilott S, Dixon L, Brison DR. The spectrum of DNA damage in human sperm assessed by single cell gel electrophoresis (Comet assay) and its relationship to fertilization and embryo development. Hum Reprod 2002; 17: 990-8.

46 Lewis SE, Agbaje IM. Using the alkaline comet assay in prognostic tests for male infertility and assisted reproductive technology outcomes. Mutagenesis 2008; 23: 163-70.

47 Enciso M, Sarasa J, Agarwal A, Fernández JL, Gosálvez J. A two-tailed Comet assay for assessing DNA damage in spermatozoa. Reprod Biomed Online 2009; 18: 609-16.

48 Gorczyca W, Gong J, Darzynkiewicz Z. Detection of DNA strand breaks in individual apoptotic cells by the in situ terminal deoxynucleotidyl transferase and nick translation assays. Cancer Res 1993; 53: 1945-51.

49 Spano M, Bonde JP, Hjollund HI, Kolstad HA, Cordelli E et al. Sperm chromatin damage impairs human fertility. The Danish First Pregnancy Planner Study Team. Fertil Steril 2000; 73: 43-50.

50 Giwercman A, Spano M, Lahdetie J, Bonde JP. Quality assurance of semen analysis in multicenter studies. Asclepios. Scand J Work Environ Health 1999; 25: 23-5; discussion 76-8.

51 Giwercman A, Richthoff J, Hjollund H, Bonde JP, Jepson K et al. Correlation between sperm motility and sperm chromatin structure assay parameters. Fertil Steril 2003; 80: $1404-12$.

52 Erenpreiss J, Elzanaty S, Giwercman A. Sperm DNA damage in men from infertile couples. Asian J Androl 2008; 10: 786-90.

53 Spano M, Kolstad AH, Larsen SB, Pacchierotti F. Diepoxybutane cytotoxicity on mouse germ cells is enhanced by in vivo glutathione depletion: a flow cytometric approach. Mutat Res 1998; 397: 37-43. 
54 Edwards RG, Brody SA. Principles and Practice of Assisted Human Reproduction. Philadelphia, , PA: WB Saunders Company; 1995.

55 Saleh RA, Agarwal A, Nada EA, El-Tonsy MH, Sharma RK et al. Negative effects of increased sperm DNA damage in relation to seminal oxidative stress in men with idiopathic and male factor infertility. Fertil Steril 2003; 79: 1597-605.

56 Boe-Hansen GB, Fedder J, Ersboll A, Ersbøll AK, Christensen P. The sperm chromatin structure assay as a diagnostic tool in the human fertility clinic. Hum Reprod 2006; 21: 1576-82.

57 Host E, Lindenberg S, Smidt-Jensen S. DNA strand breaks in human spermatozoa: correlation with fertilization in vitro in oligozoospermic men and in men with unexplained infertility. Acta Obstet Gynecol Scand 2000; 79: 189-93.

58 Simon L, Brunborg G, Stevenson M, Lutton D, McManus J et al. Clinical significance of sperm DNA damage in assisted reproduction outcome. Hum Reprod 2010; 25: 1594 608.

59 Payne JF, Raburn DJ, Couchman GM, Price TM, Jamison MG et al. Redefining the relationship between sperm deoxyribonucleic acid fragmentation as measured by the sperm chromatin structure assay and outcomes of assisted reproductive techniques. Fertil Steril 2005; 84: 356-64.

60 Larson KL, DeJonge CJ, Barnes AM, Jost LK, Evenson DP. Sperm chromatin structure assay parameters as predictors of failed pregnancy following assisted reproductive techniques. Hum Reprod 2000; 15: 1717-22.

61 Gandini L, Lombardo F, Paoli D, Euleteri P, Leter G et al. Full-term pregnancies achieved with ICSI despite high levels of sperm chromatin damage. Hum Reprod 2004; 19: 1409-17.

62 Virro MR, Larson-Cook KL, Evenson DP. Sperm chromatin structure assay (SCSA) parameters are related to fertilization, blastocyst development, and ongoing pregnancy in in vitro fertilization and intracytoplasmic sperm injection cycles. Fertil Steril 2004; 81: 1289-95.

63 Li Z, Wang L, Cai J, Huang H. Correlation of sperm DNA damage with IVF and ICSI outcomes: a systematic review and meta-analysis. J Assist Reprod Genet 2006; 23: 367-76.

64 Bungum M, Humaidan P, Spano M, Jepson K, Bungum L et al. The predictive value of sperm chromatin structure assay (SCSA) parameters for the outcome of intrauterine insemination, IVF and ICSI. Hum Reprod 2004, 19: 1401-8.

65 Sakkas D, Urner F, Bianchi PG, Bizarro D, Wagner I et al. Sperm chromatin anomalies can influence decondensation after intracytoplasmic sperm injection. Hum Reprod 1996; 11, 837-43.

66 Hammadeh ME, Zeginiadov T, Rosenbaum P, Georg T, Schmidt W et al. Predictive value of sperm chromatin condensation (aniline blue staining) in the assessment of male fertility. Arch Androl 2001; 46: 99-104.

67 Tomlinson MJ, Moffatt O, Manicardi GC, Bizarro D, Afnan M et al. Interrelationships between seminal parameters and sperm nuclear DNA damage before and after density gradient centrifugation: implications for assisted conception. Hum Reprod 2001; 16: 2160-5.

68 Tomsu M, Sharma V, Miller D. Embryo quality and IVF treatment outcomes may correlate with different sperm comet assay parameters. Hum Reprod 2002; 17 1856-62.
69 Henkel R, Hajimohammad M, Stalf T, Hoogendijk C, Mehnert C et al. Influence of deoxyribonucleic acid damage on fertilization and pregnancy. Fertil Steril 2004; 81 965-72.

70 Huang CC, Lin DP, Tsao HM, Cheng TC, Liu CH et al. Sperm DNA fragmentation negatively correlates with velocity and fertilization rates but might not affect pregnancy rates. Fertil Steril 2005; 84: 130-40.

71 Nasr-Esfahani MH, Salehi M, Razavi S, Anjomshoa M, Rozbahani S et al. Effect of sperm DNA damage and sperm protamine deficiency on fertilization and embryo development post-ICSI. Reprod Biomed Online 2005; 11: 198-205.

72 Seli E, Gardner DK, Schoolcraft WB, Moffatt O, Sakkas D. Extent of nuclear DNA damage in ejaculated spermatozoa impacts on blastocyst development after in vitro fertilization. Fertil Steril 2004; 82: 378-83.

73 Aitken RJ, Baker MA. Oxidative stress and male reproductive biology. Reprod Ferti Dev 2004; 16: 581-8.

74 Liu $\mathrm{CH}$, Tsao HM, Cheng TC, Wu HM, Huang CC et al. DNA fragmentation, mitochondrial dysfunction and chromosomal aneuploidy in the spermatozoa of oligoasthenoteratozoospermic males. J Assist Reprod Genet 2004; 21: 119-26.

75 Erenpreiss J, Bungum M, Spano M, Elzanaty S, Orbidans J et al. Intra-individual variation in sperm chromatin structure assay parameters in men from infertile couples: clinical implications. Hum Reprod 2006; 21: 2061-4.

76 Oleszczuk K. Intra-Individual Variation of SCSA-DFI. Malmö: Skanes University Hospital; 2010.

77 Aitken RJ, de Iuliis GN. Value of DNA integrity assays for fertility evaluation. Soc Reprod Fertil Supp/ 2007; 65: 81-92.

78 The clinical utility of sperm DNA integrity testing. Fertil Steril 2008; 90: S178-80.

79 Collins JA, Barnhart KT, Schlegel PN. Do sperm DNA integrity tests predict pregnancy with in vitro fertilization? Fertil Steril 2008; 89: 823-31.

80 Zini A, Boman JM, Belzile E, Ciampi A. Sperm DNA damage is associated with an increased risk of pregnancy loss after IVF and ICSI: systematic review and metaanalysis. Hum Reprod 2008; 23: 2663-8.

81 Barratt CL. Male infertility joins the translational medicine revolution. Sperm DNA from basic science to clinical reality. Mol Hum Reprod 2010; 16: 1-2.

82 Lewis SE, Agbaje I, Alvarez J. Sperm DNA tests as useful adjuncts to semen analysis. Syst Biol Reprod Med 2008; 54: 111-25.

83 Greco E, lacobelli M, Rienzi L, Ubaldi F, Ferrero S et al. Reduction of the incidence of sperm DNA fragmentation by oral antioxidant treatment. J Androl 2005; 26 349-53.

84 Greco E, Romano S, Iacobelli M, Ferrero S, Baroni E et al. ICSI in cases of sperm DNA damage: beneficial effect of oral antioxidant treatment. Hum Reprod 2005; 20 2590-4.

85 Menezo YJ, Hazout A, Panteix G, Robert F, Rollet J et al. Antioxidants to reduce sperm DNA fragmentation: an unexpected adverse effect. Reprod Biomed Online 2007; 14 418-21.

86 Moskovtsev SI, Lecker I, Mullen JB, Jarvi K, Willis K et al. Cause-specific treatment in patients with high sperm DNA damage resulted in significant DNA improvement. Syst Biol Reprod Med 2009; 55: 109-15.

87 Song GJ, Norkus EP, Lewis V. Relationship between seminal ascorbic acid and sperm DNA integrity in infertile men. Int J Androl 2006; 29: 569-75. 